\title{
Cardiothoracic surgery training in the United Kingdom
}

\author{
Mustafa Zakkar, PhD, FRCS(CTh), ${ }^{\text {a }}$ Umberto Benedetto, PhD, MD, ${ }^{a}$ Gianni D. Angelini, MD, FRCS, ${ }^{a}$ \\ Gavin Murphy, FRCS(CTh), ${ }^{b}$ Rajesh Shah, FRCS(CTh), ${ }^{\mathrm{c}}$ Marjan Jahangiri, FRCS(CTh), ${ }^{\mathrm{d}}$ and \\ Richard Page, FRCS(CTh) ${ }^{\mathrm{e}}$
}

\footnotetext{
From the ${ }^{\mathrm{a} B r i s t o l}$ Heart Institute, University of Bristol, School of Clinical Sciences, Bristol; ${ }^{\mathrm{b}}$ Department of Cardiovascular Sciences, University of Leicester, Clinical Sciences Wing, Glenfield General Hospital, Leicester; 'Department of Cardiothoracic Surgery, University Hospital of South Manchester NHS Foundation Trust, Manchester; ${ }^{\mathrm{d}}$ Department of Cardiothoracic Surgery, St George's Hospital, University of London, London; and ${ }^{\mathrm{e}}$ Department of Cardiothoracic Surgery, Liverpool Heart and Chest Hospital, Liverpool, United Kingdom.

This research was supported by the National Institute for Health Research Biomedical Research Centre at the University Hospitals Bristol NHS Foundation Trust and the University of Bristol.

Received for publication Sept 29, 2018; revisions received Nov 2, 2018; accepted for publication Nov 12, 2018; available ahead of print Jan 17, 2019

Address for reprints: Mustafa Zakkar, PhD, FRCS(CTh), Bristol Heart Institute, University Hospitals Bristol NHS Foundation Trust and University of Bristol, Marlborough St, BS2 8HW, Bristol, United Kingdom (E-mail: mustafazakkar@me.com).

J Thorac Cardiovasc Surg 2019;157:1948-55

$0022-5223 / \$ 36.00$

Crown Copyright (C) 2018 Published by Elsevier Inc. on behalf of The American Association for Thoracic Surgery https://doi.org/10.1016/j.jtcvs.2018.11.076
}

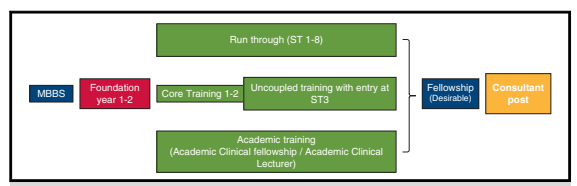

Summary of CT training pathway in the United Kingdom.

\section{Central Message}

CT surgical training in the United Kingdom is popular, competitive, and capable of producing world-class surgeons. The training program is spread over a period of at least 6 years and involves regular competence-based assessments and multiple examinations.

See Commentary on page 1956.

\section{History of Cardiothoracic Surgery (CT) in the United Kingdom}

In the 19th century, the accepted wisdom was that "no man who wishes to retain the respect of his colleagues would dare attempt a suturing of the heart." ${ }^{1,2}$ This concept was challenged by many, such as Axel Hermansen Cappelen, then Ludwig Rehn in Germany, who successfully sutured an actively bleeding wound in the right ventricle of a patient who had been stabbed, and cardiac surgery was born. ${ }^{1,2}$

The United Kingdom was one of the leading countries in the world in which significant advancements in CT were made. Henry Souttar, in 1925, successfully operated on a young patient with mitral valve disease, making it the first successful operation anywhere in the world on a patient's heart valve. However, despite technological developments in the field of cardiopulmonary bypass in the 1930s and 1940s in the United States, the focus in the United Kingdom was on thoracic surgery, dealing with tuberculosis and its complications.

Russell Brock, who worked at The Royal Brompton Hospital and Guy's Hospital, was one of the pioneers who led the way in cardiac surgical innovation and promoted operations to open the pulmonary valve in patients with pulmonary valve stenosis. He also was one of the first surgeons in his field to record surgical outcomes methodically.

The 1950s saw rapid expansion of procedures to deal with congenital or valvular heart diseases in the United Kingdom, which were largely palliative and associated with rather high mortality and morbidity. The 1960 to 1980 s, the era of coronary artery surgery and the first heart transplant, saw the United Kingdom establishing a firstclass reputation in the cardiac surgery accredited to pioneers such as Donald Ross, Terence English, and Magdi Yacoub.

Moreover, the United Kingdom has always been in the front of innovation and development of thoracic surgery, which was initially focused on dealing with pulmonary tuberculosis by surgeons such as Sir William Macewen and Holmes Sellors. After the Second World War, the United Kingdom was one of the most advanced countries in thoracic surgery, with increasing collaboration between surgeons and physicians, which continued to date by the outstanding work of more recent surgeons such as Peter Goldstraw.

Initially, CT was highly centralized in London; however, this started to change at the end of 1970s, as newer regional UK centers were established and provided new excellent opportunities for clinical work, training, and research.

\section{The Society for Cardiothoracic Surgery in Great Britain \& Ireland (SCTS)}

The SCTS was founded in 1934 and was initially devoted to the practice of thoracic surgery. After World War II, with such pioneers as Lord Brock and Sir Thomas HolmesSellors, cardiac surgery was introduced and the number of cardiothoracic surgeons progressively increased. The SCTS as an independent, self-funded organization is the representative body for $\mathrm{CT}$ in Great Britain and Ireland and aims to improve the quality of care provided to patients, guides the direction of education and development of 
surgeons in training, and supports education and professional development.

SCTS has pioneered data collection and analysis in CT surgery. Many Western countries and in more recent years other surgical specialties have followed this practice. SCTS founded the Cardiac Surgical Register in 1977, as a national record of all cardiac surgical procedures with inhospital mortality. The Thoracic Surgery Register commenced in 1980. The current UK adult cardiac surgical database collects include information about the patient's demographics, preoperative clinical characteristics, type of operation, and postoperative outcomes, mainly mortality and more recently major complications such as stroke. These data are collected as unit-specific and surgeonspecific information and is submitted by each unit to National Institute of Cardiovascular Outcome Research. The data are analyzed annually, published in 3-year periods of activity and available on SCTS Web site. ${ }^{3}$ Surgery for congenital cardiac disease is the subject of a separate audit within National Institute of Cardiovascular Outcome Research.

For thoracic surgery, the Lung Cancer Clinical Outcomes Publication is a mandatory audit of outcomes after surgery for lung cancer within the National Health Service (NHS) in England.

According to the database, there are more than 34,000 adult cardiac operations performed per year in different centers around the United Kingdom (Figure 1) with excellent overall survival rates and continuously diminishing operative mortality despite an increase in the patients' risk profiles (Figure 2). ${ }^{3}$

\section{The Royal Colleges of Surgeons (RCS)}

There are 4 different RCS in the United Kingdom, which work in collaboration and are dedicated to enabling surgeons to achieve and maintain the highest standards of surgical practice and patient care. Historically, each college held it is membership examinations (MRCS) independently.
This changed in 2004 with the emergence of a unified syllabus and examination known as the Intercollegiate MRCS.

There are currently 10 surgical specialties, including CT surgery, in which a trainee can specialize after completing their basic surgical training. The responsibility for setting the standards for surgery rests with the General Medical Council (GMC), and these are actioned by the RCS, which operate through the Joint Committee of Surgical Training (JCST) and its Specialty Advisory Committees (SACs) and Core Surgical Training Committees. Postgraduate Medical Deaneries and/or Local Education and Training Boards and their Schools of Surgery are responsible for running training programs, which are approved by the GMC and work with the SACs in the recruitment and selection to all levels of pre-Certification training. In the Republic of Ireland, these roles are undertaken by the RCS Ireland and Medical Council of Ireland.

CT surgical training in the United Kingdom is a broad specialty and includes general and specialized adult cardiac surgery, adult thoracic surgery, and congenital cardiac surgery. The latter subspecialty cares for both children and adults who require surgery for congenital heart defects.

\section{OVERVIEW OF CT TRAINING IN THE UNITED KINGDOM}

After 5 to 6 years of undergraduate study at a university medical school, there follows the 2-year Foundation Program (FY1-2), which all UK medical graduates must undertake before achieving registration of a license to practice medicine in the United Kingdom; this is overseen by the UK General Medical Council. They then progress to postgraduate specialty training (ST).

Training in surgery involves core training and ST. Core surgical training 1 to 2 lasts 2 years and provides training in a range of surgical specialties, which can include 6 to 12 months in CT surgery. It is expected that the trainee will pass the MRCS during the first 2 years of training before entering specialty training (ST3-8). Toward the end

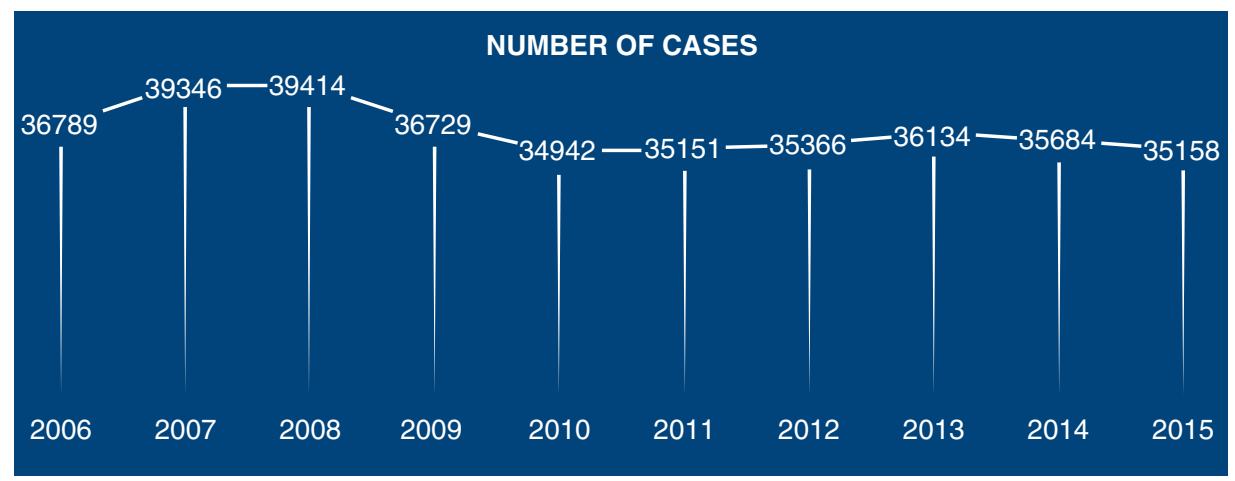

FIGURE 1. Number of all adult cardiac operations in the United Kingdom on yearly bases from 2006. (reproduced with permission from National Institute of Cardiovascular Outcome Research). 


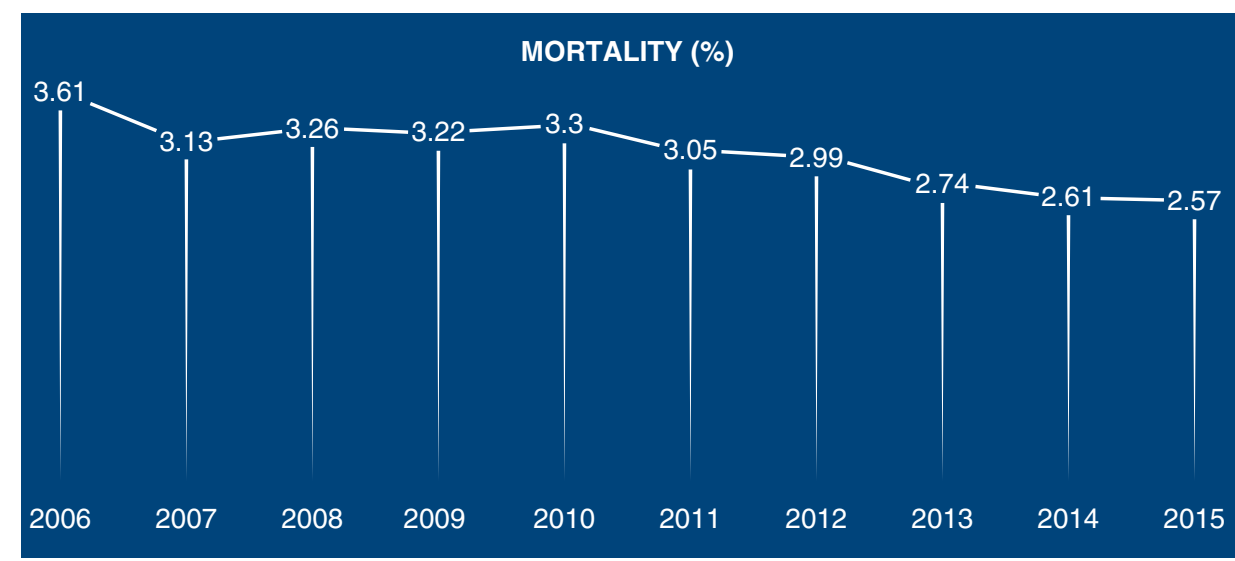

FIGURE 2. Overall mortality after adult cardiac operations in the United Kingdom on yearly bases from 2006. (reproduced with permission from National Institute of Cardiovascular Outcome Research).

of this training, completion of the intercollegiate exit examination leading to specialty fellowship of the RCS is required (FRCS [CTh]). After the completion of training, trainees who apply for a consultant post in the United Kingdom require a Certificate of Completion of Training (CCT) (or an equivalent certificate of eligibility for specialist registration) to be appointed. In addition to core training, as described to follow, there is the option of runthrough training, where trainees who are certain of their specialty choice can compete for entry into the specialty as ST1-2 and continue until certification (Figure 3).

\section{Training Centers}

The training centers are accredited by the GMC with advice as to their suitability for this provided by the SAC. There are recognized criteria for a center to be suitable for training. The number of recognized training posts in each center or region is determined by a combination of workforce planning and capacity for training within each training region. This is approved by Health Education
England and the Regional (Deanery) Schools of Surgery in conjunction with the SAC.

\section{Selection into CT Training}

In the United Kingdom, the 6-year program (ST3-ST8) was introduced in 9 surgical specialties in 2008, whereby candidates are chosen through National Selection. The $\mathrm{SAC}$ is responsible for developing person specifications for selection into the specialty. ${ }^{4}$ Selection takes place within a national process overseen by the SAC and in the Republic of Ireland, by the Royal College of Surgeons in Ireland. Entry into the specialty is by competition with well-defined criteria and candidate specification. The general person specification for candidates includes the ability to provide evidence of career progression and present level of achievement and performance which is appropriate with the totality of their period of training. The candidate must also have satisfactorily completed an approved Core Surgical Training program or equivalent as well as the relevant competencies in CT surgery as described in the Core Surgical

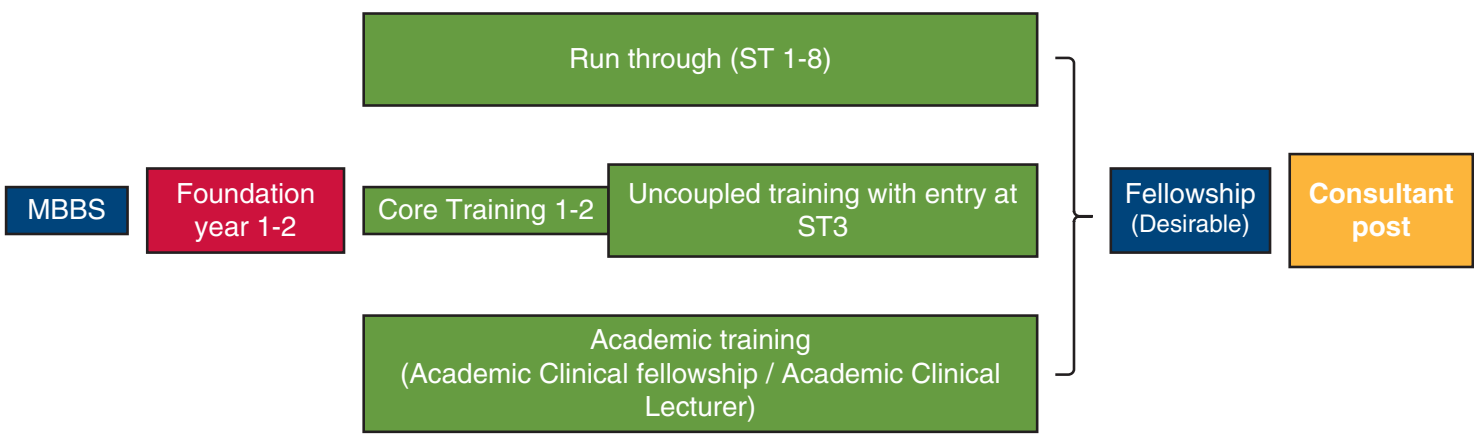

FIGURE 3. Schematic overview of the cardiothoracic surgery training pathway in the United Kingdom. After graduation from medical school and completing the foundation year 2 program, there are different pathways for entering cardiothoracic surgery, which includes the run-through, uncoupled training (after finishing 2 years of core training), and academic training. After the completion of training, trainees can either apply for a fellowship to increase skills or apply for a consultant post. $M B B S$, Medicinae Baccalaureus Baccalaureus Chirurgiae; ST, specialty training. 
TABLE 1. Requirement of completion of cardiothoracic training

\begin{tabular}{|c|c|}
\hline \multicolumn{2}{|c|}{ Guidelines for cardiothoracic surgery certification } \\
\hline $\begin{array}{l}\text { Clinical } \\
\text { experience }\end{array}$ & $\begin{array}{l}\text { 1. Trainees should have had exposure to both } \\
\text { adult cardiac and thoracic surgery. } \\
\text { 2. Trainees must be able to demonstrate that they } \\
\text { are keeping their knowledge and skills up-to- } \\
\text { date. } \\
\text { 3. Trainees must be able to demonstrate } \\
\text { knowledge and understanding of the } \\
\text { management of the following critical } \\
\text { conditions: } \\
\text { - Aortic dissection; } \\
\text { - Stridor; } \\
\text { - Secondary pneumothorax/tension } \\
\text { pneumothorax; } \\
\text { - Cardiac tamponade; } \\
\text { - Acute hemothorax; } \\
\text { - Low cardiac output following cardiac } \\
\text { surgery; } \\
\text { - Endocarditis-native or prosthetic valve; } \\
\text { and } \\
\text { - Respiratory failure following thoracic } \\
\text { surgery. }\end{array}$ \\
\hline
\end{tabular}

$\begin{aligned} & \text { Operative } \\ & \text { experience }\end{aligned}$
$\begin{aligned} & \text { 1. There are indicative numeric requirements for } \\ & \text { the number of operations performed. This has } \\ & \text { been agreed as } 250 \text { major cases with the } \\ & \text { majority in the area of special interest. }\end{aligned}$
$\begin{aligned} & \text { 2. Candidates should demonstrate broad } \\ & \text { exposure to operative cardiothoracic surgery } \\ & \text { with the majority of procedures in the area of } \\ & \text { special interest. }\end{aligned}$
$\begin{aligned} & \text { Trainees should demonstrate competence across } \\ & \text { a broad range of cardiothoracic procedures, as } \\ & \text { evidenced by completed procedure-based } \\ & \text { assessments. }\end{aligned}$

\begin{tabular}{|c|c|}
\hline Research & $\begin{array}{l}\text { 1. Trainees should provide evidence of study of } \\
\text { research methodology or possess a higher } \\
\text { degree. } \\
\text { 2. Trainees should have } 4 \text { papers published in } \\
\text { peer-reviewed journals, } 2 \text { of which should be } \\
\text { completed as first author. } \\
\text { 3. Trainees should have delivered } 6 \\
\text { presentations at national/international } \\
\text { meetings, } 2 \text { of which must have been } \\
\text { presented internationally. } \\
\text { 4. Trainees should have completed a Good } \\
\text { Clinical Practice course in Research } \\
\text { Governance and a research methodologies } \\
\text { course. }\end{array}$ \\
\hline $\begin{array}{l}\text { Quality } \\
\text { improvement }\end{array}$ & $\begin{array}{l}\text { Trainees should have evidence of an audit } \\
\text { completed (loop closed) within the } 2 \text { y before } \\
\text { certification. }\end{array}$ \\
\hline $\begin{array}{l}\text { Medical education } \\
\text { and training }\end{array}$ & $\begin{array}{l}\text { Trainees should have completed courses in } \\
\text { training and education by the time they apply } \\
\text { for certification. }\end{array}$ \\
\hline
\end{tabular}

(Continued)
TABLE 1. Continued

\begin{tabular}{cc}
\hline \multicolumn{2}{c}{ Guidelines for cardiothoracic surgery certification } \\
\hline $\begin{array}{c}\text { Management } \\
\text { and leadership }\end{array}$ & $\begin{array}{c}\text { Trainees should have completed courses in NHS } \\
\text { management by the time they apply for } \\
\text { certification. }\end{array}$ \\
$\begin{array}{c}\text { Educational } \\
\text { conferences }\end{array}$ & $\begin{array}{c}\text { Trainees should have attended a major national or } \\
\text { international meeting in each year of training. } \\
\text { Training programs require attendance at a } \\
\text { minimum of } 70 \% \text { of the regional teaching } \\
\text { days. }\end{array}$ \\
\hline
\end{tabular}

NHS, National Health Service.

Training curriculum. In 2013 entry into run-through training from the ST1 level commenced.

Following short-listing from a detailed written application, candidates are invited to a selection center for interview. The process of national selection takes place over 2 days with approximately 40 consultant CT surgeons as assessors. The interview process is multistep and includes assessment of the candidates' portfolio, structured interviews, dexterity assessments using the Objective Structured Assessment of Technical Skills, and interview scenarios with patients (real patients are not invited, only actors) which includes consenting of patients.

The number of trainees accepted every year is approximately 15 to 20, including both entry at ST1 and ST3 levels, although the proportion of candidates applying for ST1 positions is increasing and ST3 decreasing. Candidates are ranked and then matched to their desired place for training. The successful candidates are offered a National Training Number in a particular region in which they rotate between different centers.

It is expected that all trainees will spend time being trained in both cardiac and thoracic surgery and reach a certain competency regardless of what subspecialty they choose after qualification. A cardiac themed trainee will spend 1 year in thoracic surgery, and a thoracic trainee will spend a year in cardiac surgery.

Training schemes can be divided into the areas that follow.

Uncoupled training with entry at ST3. This has been the most common pathway for entry into CT surgical specialist training in the United Kingdom. It involves completion of years 1 and 2 in Core Training, when trainees attain common surgical knowledge and skills as well as generic professional behaviors, and is followed by competitive entry into CT surgical training at the ST3 level.

Run-through training with entry at ST1. In this scheme, competitive and direct entry into specialist training at ST1 level is possible with run-through training to CCT at ST8. The run-through program in the United Kingdom is similar to the integrated training program in the United States, which encompasses CT residency training from the time 
of graduation from medical school to completion, thus bypassing other placements in other surgical specialties. The rationale behind run-through training is to provide more job security and potentially save time in total years of training and increasing the overall experience in CT surgery. There is a seamless transition from ST2 to ST3, where trainees can establish themselves within institutions and develop strong links with their trainers. However, there is a potential disadvantage in that CT surgeons may be less experienced in the generality of surgery. This has been recognized in the United States, with ineligibility for American Board of Surgery certification and the lack of a "chief year" experience in general surgery.

Academic training. Some trainees choose to spend a dedicated period of time in research and obtaining a higher postgraduate degree. Thus, different Deaneries offer the option of combined clinical and academic training. Appointment into academic training is usually carried out during the National Selection interviews. Candidates applying for academic training posts will have additional interviews during the selection process where they are required to demonstrate an understanding of basic research principles, methodology and ethics and evidence of relevant academic and research achievements. The academic training programs are carefully designed to provide both academic and clinical training at the highest level. The annual clinical skills assessment is the same for academic and nonacademic trainees; however, academic trainees will have additional assessment of their academic progress annually at the Annual Review of Competence Progression (ARCP). Work rotas for academic trainees differ from nonacademic and different units will have an approved time tables for academic trainees that takes into account both clinical and academic needs, which are usually approved by the deanery and university. There is understanding that due to the nature of combined academic and clinical work some academic trainees will need to stay in the training program longer, but this is usually done on individual needs at the local ARCP.

\section{THE CURRICULUM}

The curriculum for Core surgical training aims to serve multiple diverse training needs. At its heart are the educational principles, assessment tools, and supervisory framework of the intercollegiate surgical curriculum. The minimum requirements for this curriculum are completion of the common content module, the core specialty module for each specialty through which the trainees rotate (which may be as few as one), and 1 ST3 preparation module (which may be in any specialty of the trainee's choice).

The curriculum aims for high-quality, safe care of surgical patients, specifying the parameters of knowledge, clinical skills, technical skills, professional behavior, and leadership skills that are considered necessary to ensure patient safety throughout the training process.
TABLE 2. Summary of major cardiac and thoracic cases

Cardiac major cases

Coronary artery bypass grafting (CABG), either alone or in combination with another procedure such as valve repair/replacement

Valve repair/replacement either alone or in combination with CABG or any other cardiac procedure

Other major cardiac surgical cases involving cardiopulmonary bypass, such as postinfarct ventricular septal defect (VSD) repair, excision of atrial myxoma, or pericardiectomy

Implantation of the heart or lung (transplantation)

Heart-lung block retrieval

Any congenital cardiac procedure (atrial septal defect, VSD closure patent ductus arteriosus ligation, etc)

Thoracic major cases

Anatomical lung resection (video-assisted thoracoscopic surgery [VATS]/robotic/open)

Correction of pectus deformity

Decortication

Thoracotomy for trauma

Chest wall resection and reconstruction

Tracheal resection

Surgery for secondary pneumothorax (VATS/open)

There are specific conditions that trainees are required to satisfy before being awarded CCT. The JCST has recently issued detailed guidelines, ${ }^{5}$ which are shown in Table 1. The table includes the number of operations performed, which is agreed as 250 major cases. The JCST also provides a clear definition to what counts as a major cardiac or thoracic case (Table 2).

\section{THE TRAINING EXPERIENCE}

There are specific milestones that allow trainees to benchmark their progress, which are the entry to surgical training, entry to specialized training (ST3), and exit at CCT. During early training stages, trainees gain proficiency in conduit harvesting before moving on to the common components of cardiac surgery, which include median sternotomy, internal thoracic artery harvesting, cannulation for bypass, and sternal closure. During this period, trainees are either assisted by the supervising consultant or more senior trainee but as they progress, they will be allowed to perform parts of operations independently. Most of the times the trainees will have to demonstrate proficiency in setting up and finishing cases before they are trained in performing the main parts of the operation under supervision. By the end of their training, they are expected to be able to perform some operations independently. Similar patterns of training are seen in thoracic surgery.

At the end of training, it is expected that trainees will be able to manage some key conditions independently. They are encouraged to arrange a fellowship in another training institution and/or gain an out-of-program 
experience in an area of the specialty that particularly interests them. Many opt to go abroad. The SCTS is among a number of organizations that fund travel bursaries for trainees.

All trainees in CT surgery are required to be actively involved in the daily management of their patients under the supervision of their clinical supervisor. Moreover, they should have the opportunity to attend a minimum of 1 consultant-supervised outpatient clinic (where they should see both new and follow-up patients) as well as one multidisciplinary team meeting each week.

The United Kingdom has demonstrated that it is feasible to train junior doctors in different aspects of conventional and complex cardiac surgery, such as beating-heart coronary artery bypass grafting and minimally invasive valve surgery with excellent outcomes, which is a reflection of the dedication of UK surgeons to train and improve patient care. . $^{6}$

During their training program, surgical trainees are required to attend certain courses including Advanced Life Support, Advanced Trauma Life Support, Basic Surgical Skills, and Care of the Critically Ill Surgical Patient. In addition, SCTS education runs a comprehensive portfolio of courses for the trainees spanning all 6 years of specialty training.

Trainees are actively encouraged to attend and contribute to surgical meetings such as the SCTS annual meeting and European Association for Cardiothoracic Surgery, the expenses for which will be usually funded by their local Deaneries.

There has recently been more emphasis on the importance of simulation training. Although it is not widely adopted, there is emerging evidence from the specialty itself in the United Kingdom, which has shown that simulation is associated with improvement of the trainees understanding and confidence. ${ }^{9,10}$

\section{TRAINEE ASSESSMENT}

The trainees are continuously assessed through workbased assessments (WBAs) and structured reports from assigned educational supervisors, which in turn contribute to the ARCP. This assesses the professional requirements expected of all doctors, including surgeons, to meet their obligations under good medical practice to remain licensed to practice. The trainee will become competent in managing patients presenting either acutely or electively with a range of symptoms and conditions. This is tested either by the WBAs and also the FRCS(CTh) examination. The final stage of the syllabus is intended to allow the CCT holder to develop a particular area of clinical interest and expertise before appointment to a consultant post.

WBAs are the method by which UK trainees are assessed throughout the training program. They are online tools that requires data input by both the trainee and the trainer.
WBAs comprise 4 different categories of assessments, which are as follows:

1. Clinical evaluation exercise: This assesses the way the trainee interacts with patients in term of attitudes, behaviors, and skills.

2. Case-based discussion: This is a structured, in-depth discussion between the trainee and the trainee's assessor about how a clinical case was managed.

3. Procedure-based assessment: assesses the trainee's technical, operative, and professional skills in a range of specialty procedures or parts of procedures during routine surgical practice up to the level of certification (Figure 4).

4. Direct observation of procedural skills: this is used to assess the trainee's technical, operative, and professional skills in a range of basic diagnostic and interventional procedures, or parts of procedures, during routine surgical practice.

The procedure-based assessment is the most thorough WBA and consists of a list of objectives with 3 possible outcomes alongside each. These outcomes are "not observed or not appropriate," "development required," or "satisfactory standard for CCT (no prompting or intervention required)." There is then an overall score for the procedure.

\section{CHALLENGES}

CT surgical training in the United Kingdom faces a number of challenges and the training organizations such as the SAC working closely with the SCTS aim to regularly refine the curriculum to overcome these challenges and provide support for the trainees. Some of the challenges are included in the sections that follow.

\section{Workforce Planning and the Changes in Surgical Profile}

There is limited number of consultant posts available annually in the United Kingdom and may not match the number of trainees who are reaching the final stages of training. This has been addressed by predicting retirement numbers combined with the knowledge of technological development and the public health issues that are affecting the specialty thus being able to provide an estimate of demand for CT surgeons in the future and match it to training places. The specialty is continuing to move toward complete separation between cardiac and thoracic surgery at the level of entry into consultant grade. However, the trainees will for the foreseeable future continue to be trained in both, although they are encouraged to express an interest for one or the other subspecialty during their training years.

Despite the optimistic views of the NHS workforce review, there are concerns surrounding the reduction in the number of cardiac operations carried out yearly, which can impact potential for training. Furthermore, the 


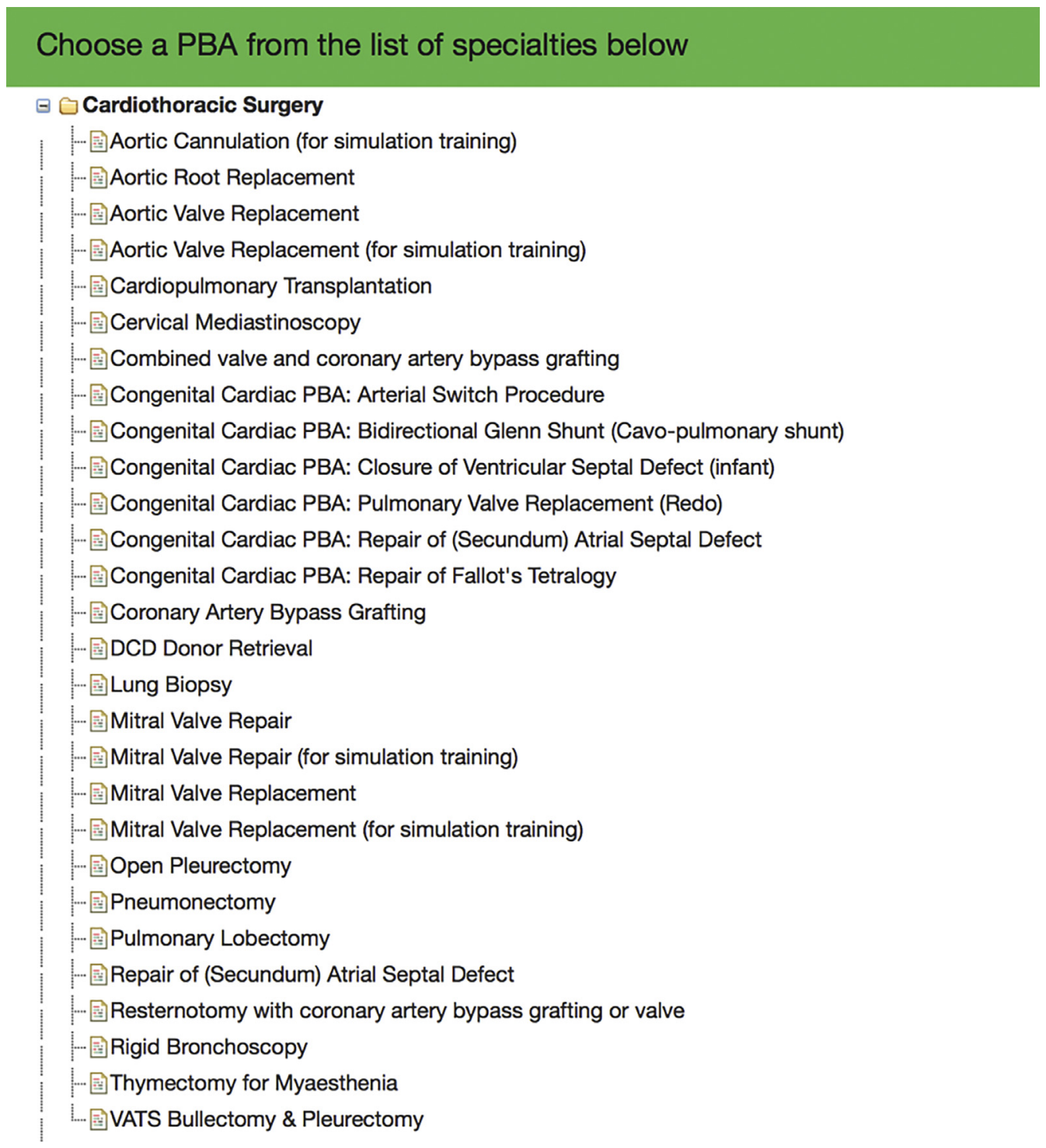

FIGURE 4. Drop list from the ISCP of all the procedures that can be part of the PBA in cardiothoracic surgery from the ISCP Web site. ISCP, Intercollegiate Surgical Curriculum Programme; $P B A$, procedure-based assessment; $D C D$, donor after cardiac death; VATS, video-assisted thoracoscopic surgery.

reciprocity of medical training recognized within the European Union (EU) means that CT surgical trainees from other countries in the EU can compete for the limited number of CT surgical consultant posts available in the United Kingdom. This can result in local trainees failing to secure consultants posts after finishing their training. Nevertheless, although there is no specific priority for UK trainees, working for many years within the NHS confers significant advantages over trainees from other European countries when applying for NHS CT consultant posts.

Another challenge for trainees is that recognized scope of the specialty of CT surgery in the United Kingdom is cardiothoracic rather than cardiovascular as in the EU. As a result, managing complex aortic pathologies (which depends on the interaction between cardiac surgeons, vascular surgeons, and interventional radiologists) is an area of practice for which UK trainees may have less exposure than those trained in other European countries.

\section{The Publication of Surgeon-Specific Data}

It is accepted throughout all health care organizations that there should be full transparency and disclosure of outcomes, so that patients are provided with clear information on the performance of hospitals and the surgeons employed there. The basic tenet of this philosophy this that publication of outcomes improves the quality of care that patients receive. A potential disadvantage is that publication of such data may result in risk-averse behavior by surgeons, thus denying many high-risk patients' surgical intervention, despite these interventions being the only hope for the 
patient surviving their disease. Also, the publication of surgeon-specific rather than hospital-specific outcomes may lead to an underestimate of the importance of the multi-disciplinary care patients receive throughout their hospital stay.

It is possible that the publication of surgeon specific data may have adversely impacted recruitment to CT surgery, a reduction in training opportunities, as well as leading to a decrease in both the proportion and variety of cases performed by trainees. ${ }^{11,12}$

\section{The Impact of the European Working Time Directive (EWTD)}

Most UK surgical trainees and trainers believe that training has suffered due to the introduction of EWTD. EWTD was introduced originally in 1993 to avoid fatigue from overwork. It initially excluded doctors, but revisions by the European Commission in 2000 required doctors-intraining employed by the NHS to comply with a 48 -hour week by 2009 . This is in stark contrast to the 80 hours per week limit in the United States for medical trainees. The decrease in working hours has resulted in decreased both elective and emergency operative experience. ${ }^{13,14}$ This is important when considering that most CT surgical emergencies, which require expert and precise treatment to ensure optimum results, tend to occur out of hours. It is therefore likely that EWTD reduces out-of-hours experience. The EWTD has led to a significant move from oncall to shift-based rotas, which are unpopular among trainees as it may reduce both the quantity and quality of their training due to the fact that a shift system usually means that the time spent with their dedicated trainer becomes fragmented. There is also reduced continuity of care for patients. ${ }^{15,16}$ Furthermore, the limited working hours and the necessity for a shift work pattern have resulted in fewer core surgical trainees rotating to CT. Therefore, with fewer junior trainees exposed to $\mathrm{CT}$ surgery, this has resulted in fewer candidates applying for CT surgical program in the United Kingdom in recent years. One of the solutions for this issue is the use of competency-based training program, which can be refined annually based on trainees' and trainers' surveys. In addition, having a mixture of trainees and middle-grade service providers (nontrainees) will with no doubt allow more theater exposure for trainees without impacting the service.

\section{CONCLUSIONS}

CT surgery training in the United Kingdom remains popular, competitive, and capable of producing world-class surgeons. Training involves regular competence-based assessments and multiple examinations. The higher specialty training program spread over a period of at least 6 years, during which trainees rotate to different centers and get appropriate exposure and training in different cardiac and thoracic conditions. Trainees are supported to choose a subspecialty during the last two years of their program. The curriculum continues to evolve to provide trainees with evidence based up-to-date training allowing for integration with other specialties such as cardiology and vascular surgery. There are several challenges facing CT surgery in the United Kingdom, including the need for continuous evolvement of the curriculum and the ability to provide more structured subspecialty training in lesser number of years accommodating the working time directives.

\section{Conflict of Interest Statement}

Authors have nothing to disclose with regard to commercial support.

\section{References}

1. Absolon K. Theodor Billroth and cardiac surgery. J Thorac Cardiovasc Surg. 1983;86:451-2.

2. Alexi-Meskishvili V, Böttcher W. Suturing of penetrating wounds to the heart in the nineteenth century: the beginnings of heart surgery. Ann Thorac Surg. 2011 92:1926-31

3. The Society for Cardiothoracic Surgery in Great Britain \& Ireland. Blue Book Online. Available at: www.bluebook.scts.org. Accessed August 30, 2018.

4. Health Education England, Wessex. Cardiothoracic Surgery ST1 \& ST3 National Recruitment 2019. Available at: www.wessexdeanery.nhs.uk/recruitment/ national_ct_surgery_st1_st3.aspx. Accessed August 30, 2018.

5. Joint Committee on Surgical Training. Available at: www.jcst.org. Accessed August 30, 2018.

6. Soppa G, Yates M, Viviano A, Smelt J, Valencia O, van Besouw JP, et al. Trainees can learn minimally invasive aortic valve replacement without compromising safety. Interact Cardiovasc Thorac Surg. 2015;20:458-62.

7. Murzi M, Caputo M, Aresu G, Duggan S, Angelini GD. Training residents in offpump coronary artery bypass surgery: a 14-year experience. J Thorac Cardiovasc Surg. 2012;143:1247-53.

8. Benedetto U, Caputo M, Gaudino M, Vohra H, Chivasso P, Bryan A, et al. How safe is it to train residents to perform coronary surgery with multiple arterial grafting? Nineteen years of training at a single institution. Semin Thorac Cardiovasc Surg. 2017;29:12-22.

9. Smelt JLC, Phillips S, Hamilton C, Fricker P, Spray D, Nowell JL, et al. Simulator teaching of cardiopulmonary bypass complications: a prospective, randomized study. J Surg Educ. 2016;73:1026-31.

10. Smelt J, Corredor C, Edsell M, Fletcher N, Jahangiri M, Sharma V. Simulationbased learning of transesophageal echocardiography in cardiothoracic surgical trainees: a prospective, randomized study. J Thorac Cardiovasc Surg. 2015; 150:22-5.

11. Khan OA, Iyengar S, Pontefract DE, Rogers V, Ohri SK, Livesey SA. Impact of surgeon-specific data reporting on surgical training. Ann R Coll Surg Engl. 2007; 89:796-8.

12. Westaby S, Baig K, De Silva R, Unsworth-White J, Pepper J. Recruitment to UK cardiothoracic surgery in the era of public outcome reporting. Eur J Cardiothorac Surg. 2015;47:679-83.

13. Desai SV, Feldman L, Brown L, Dezube R, Yeh HC, Punjabi N, et al. Effect of the 2011 vs 2003 duty hour regulation-compliant models on sleep duration, trainee education, and continuity of patient care among internal medicine house staff a randomized trial. JAMA Intern Med. 2013;173:649-55.

14. Connors RC, Doty JR, Bull DA, May HT, Fullerton DA, Robbins RC. Effect of work-hour restriction on operative experience in cardiothoracic surgical residency training. J Thorac Cardiovasc Surg. 2009;137:710-3.

15. West D, Codispoti M, Graham T; Specialty Advisory Board in Cardiothoracic Surgery of The Royal College of Surgeons of Edinburgh. The European Working Time Directive and training in cardiothoracic surgery in the United Kingdom. Surgeon. 2007r;5:81-5. quiz 85, 121.

16. Lim E, Tsui S; Registrars and Consultant Cardiac Surgeons of Papworth Hospital 2003-2005. Impact of the European Working Time Directive on exposure to operative cardiacsurgical training. Eur J Cardiothorac Surg. 2006;30:574-7. 